\title{
AN OVERVIEW OF ADVERSE REACTIONS CAUSED BY PROSTHETIC BIOMATERIALS
}

Soniya R. Niraspatil ${ }^{1}$, Pravin S. Purnale², Aruna J. Bhandari'3, Gangadhar S.A4, Bharat A Deosarkar ${ }^{5}$

\section{HOW TO CITE THIS ARTICLE:}

Soniya R Niraspatil, Pravin S Purnale, Aruna J Bhandari, Gangadhar SA, Bharat A Deosarkar. "An overview of adverse reactions caused by prosthetic biomaterials". Journal of Evolution of Medical and Dental Sciences 2013; Vol. 2, Issue 44, November 04; Page: 8508-8516.

ABSTRACT: Providing dental treatment involves the use of a wide range of materials within prosthodontic practice and many of these materials pose a potential occupational risk as well as a risk to the patient. The range and complexity of materials employed in practice is increasing, and the pressures on manufacturers and clinicians are likely to maintain this trend. While the introduction of new materials brings great benefits, there is always a risk of an adverse reaction to one or more components by members of the dental team or members of the public. Pre-market biocompatibility testing cannot guarantee absolute safety, so it is important to identify materials that can cause an adverse reaction when placed on the open market. There are no materials that can be considered as absolute safe under all conditions, for all patients and dental personnel, but it is essential that the adverse events that do occur are monitored and treated appropriately.

INTRODUCTION Today's prosthodontic treatment aspires to fulfill high aesthetic demands. New materials are frequently introduced to dentistry. Ceramics, metals, polymer-based materials, and combinations of materials offer multiple treatment possibilities in prosthodontic treatment.

Biomaterials in prosthodontic dentistry encompass impression materials, luting cements, and restorative materials like metal alloys, ceramics and polymeric resins. The aim of this article is to give a report on factors that may influence the frequency of adverse reactions to biologic tissues. Some of the adverse reactions may be due to lack of knowledge about the toxic, irritant and allergenic properties of dental materials.

Release of components from prosthetic biomaterials: The release of substances from dental materials is considered to be gradual and occur in small amounts [1]. Alloys used in prosthodontics have been shown to release ions like $\mathrm{Ni}, \mathrm{Cr}, \mathrm{Be}$ and also $\mathrm{Pd}$ may be eluted into the oral cavity.Co is released as ion by a process of alloy corrosion, and $\mathrm{Cd}$ has been found to be eluted from dentures [2$4]$.

In most reports on compounds released from dentures made of acrylate, only the monomer methyl methacrylate has been detected [5-9]. The elution of methacrylic acid and benzoic acid to artificial saliva, showed that formaldehyde may be eluted from heat cure polymer and aromatic compounds dibutyl phthalate, phenyl benzoate, phenyl salicylate are also eluted from the same [10 12]. Soft-tissue lining materials based on (poly) ethyl methacrylate for prosthetic use have also been shown to release high amounts of phthalate esters.

Fate of released substances in the human body from prosthetic materials: Compounds released from dental materials are supposed to be absorbed in the gastrointestinal tract, in the oral mucosa, from the skin, or in the respiratory system.The mechanism for this absorption depends on the 
nature of the chemical properties of the released elements whether they exist as ions, hydrophilic and lipophilic compounds, volatile substances, or particles. The molecular transport through cell membranes may be by an active transport mechanism. Active transport requires energy and must in some way be linked to energy metabolism [13].

ADVERSE REACTIONS: Adverse reactions to prosthodontic materials may occur as a result of their direct contact with soft or mineralized tissues, or by exposure to leachable components resulting from corrosion and degradation products.

Immunotoxicology is an adverse or inappropriate change in the structure or function of the immune system after exposure to a foreign substance. Hypersensitivity reactions can be divided into four types: type I, type II, type III and type IV, based on the mechanisms involved and time taken for the reaction, most hypersensitivities to dental materials appear to be delayed type reactions, although reports of other types exist $[14,15]$.

There is no pathognomonic sign or symptom, nor one specific test for hypersensitivity. It is diagnosed on the basis of a careful and detailed history, presenting signs and symptoms (Table.1) and, clinical tests. Epicutaneous patch tests are often used to assess whether skin reactions are elicited by primary irritants or via the amplifying mechanisms of the immune system [16].

Impression Materials: Materials used for dental impressions are usually safe. Though a study reported a fatal anaphylactic shock due to irreversible hydrocolloid impression material, the substance hypothesized as a trigger factor was Kromopan, which is not a known allergenic or anaphylactoid. Kromopan is an alginate used to make high-precision impressions with chromatic phase in dicators [17].

Elastomeric impression materials were also reported to evoke allergic reactions. Several cases of polyether contact dermatitis and stomatitis have been reported. Most of the cases are due to prolonged contact with the catalyst of the polyether rubber impression material [18]. The catalyst as well as the freshly mixed polyether elicited positive skin reaction interpreted as being delayed hypersensitivity reaction [19]. The base material of polysulfide consists of low molecular weight organic polymer containing a reactive mercaptan $(-\mathrm{SH})$ group and $20 \%$ reinforcing agent such as titanium dioxide, zinc sulfate, copper, carbonate or silica. The catalyst is composed of lead dioxide with or without manganese dioxide and inert oil [20,21]. Contact of these elements with living tissues in the mouth may induce adverse tissue reaction such as foreign body reaction, toxicity and hypersensitivity. The most likely induced problem for the patient arises from pieces of impression material being left in the sulcus.

Zinc oxide eugenol is widely used for making final impressions; however eugenol is generally cytotoxic at high concentrations and has an adverse effect on fibroblasts and osteoblast cells. Thus, at high concentrations it produces necrosis and reduced healing. In lower concentrations, eugenol can act as a contact allergen evoking a localized delayed hypersensitivity reaction. [22]

Luting Cements: Zinc-phosphate cement it is the most frequently used luting agent for crowns and bridges. Pulpal reactions initially occurring in deep cavities will subside over the time. Uncertainty has also existed about glass ionomer cements, because clinical reports have indicated a high frequency of post-luting sensitivity. Pulp studies generally indicate slight reactions [23], but 


\section{REVIEW ARTICLE}

somewhat more to the luting type than to the restorative type of glass ionomer materials. A clinical study of pulp sensitivity following cementation with zinc phosphate and glass ionomer cements showed less sensitivity to zinc phosphate than to glass ionomer during the first 2 weeks, but after 3 months, there were no differences[24]. The pressure on the dentine exerted during cementation was thought to play a possible role on the observation.

Regarding modern resin-based luting cements, it is known that HEMA (2-Hydroxy ethyl methacrylate) is released from these materials, which has a variety of damaging biological properties, ranging from pulpal inflammation to allergic contact dermatitis. These are therefore potential hazards from resin-modified glass ionomers. However, clinical results with these materials that have been reported to date are generally positive [25].

Metal and alloys: Biological reactions to casting alloys (Table.2) are dependent on the release of components from the alloys, which would seem to indicate that they should be dependent on the degree of corrosion. However, no correlation seems to exist between mucosal reactions to fixed prostheses and corrosion and tarnish [26]. This lack of correlation may indicate that the biological reactions observed are caused by factors other than the material per se. Palladium alloys are generally better tolerated than base-metal alloys or gold alloys for metal-ceramic restorations, although they tend to tarnish more than other casting alloys. Palladium alloys have also been reported to cause adverse reactions, and palladium may be linked to cross-reactivity with $\mathrm{Ni}$ [26]. Cadmium has been used in solders, but its presence is not considered to have an effect on patients because of the minimal amounts present. However, technicians who frequently braze alloys above their melting point are at risk because in the process of soldering and welding, Cadmium will evaporate. This represents a problem with the need for availability of an adequate fume extraction system. In response to this hazard, the use of solders containing Cadmium has also been largely discontinued.

Literature indicates that allergic reactions to gold-based restorations were more common than to Ni containing alloys [27]. A study indicated a possible association between a defective gold crown and cancer of the tongue [28]. Gingivitis and stomatitis were the most common clinical symptoms. However, mucosal reactions to metal-based partial dentures are rare

Titanium is considered by some to be non-allergenic but reactions have been reported and titanium ions are found throughout the body. A hypersensitivity reaction to titanium may have devastating results since the material is used in implanted devices such as pacemakers, dental implants, stents, orthodontic brackets, and eyeglass frames. Sensitivity to titanium is characterized by the local presence of abundant macrophages and $\mathrm{T}$ lymphocytes and the absence of $\mathrm{B}$ lymphocytes, indicating type IV hypersensitivity. $[29,30]$

Ceramics: The main hazard to the laboratory technician, and less so to the dentist, during the fabrication of dental porcelain restorations are the prolonged exposure to finely divided inorganic porcelain dust. Silicosis, a fibrotic pulmonary disease resembling tuberculosis or sarcoidosis, affects workers exposed to siliceous dust in the ceramics industry [31]. The dental laboratory technician is exposed to siliceous material from a variety of sources in the dental laboratory: investments, sandblasters, grinding and polishing wheels, dental ceramics, filled resin products, and polishing agents. Silica exposure has also been associated with the development of malignant histiocytic lymphomas, 
squamous cell carcinomas, and adenocarcinomas in several rat strains [32]. It appears that silicosis renders the silicotic approximately twice as susceptible to lung cancer as the general population [33].

Localized tissue reaction like silica granulomas have been reported where silica-containing materials have been implanted in tissue. The etiology of silica granulomas is thought to be either delayed-type hypersensitivity [34] or else a non-allergic, foreign-body reaction to a colloidal substance [35]. The nodular, sometimes pigmented lesions may appear after an asymptomatic latent period of 15 years or more [36].

Little is known about the leachability of components from dental ceramic materials but most dental ceramics are regarded as generally inert materials. Two main possibilities exist regarding systemic effects of dental porcelains a) leaching of siliceous material with formation of colloidal silica and a silica granuloma at a distant site, and b) leaching of fluorescing agents, rare-earth pigments, opacifiers, and other ingredients, with possible adverse systemic effects.

Polymer materials: Resin-based materials comprising of liquid methyl-meth-acrylate (MMA) monomers and poly-methyl--meth-acrylate (PMMA) powder are the most commonly used polymers in dental prostheses. The setting of restorative materials and adhesives is initiated chemically by mixing two components or by visible light. In both cases, polymerization is incomplete and monomers, not reacted (also known as free monomers), are released [37]. These free monomers may cause a wide range of adverse health effects such as irritation to skin, eyes or mucous membranes, allergic dermatitis, asth ma and paraesthesia in the fingers. Additionally, disturbances of the central nervous system such as headache, pain in the extremities, nausea, loss of appetite, fatigue, sleep disturbances, irritability, loss of memory, and changes in blood parameters may also be noted. [38]

MMA monomer may result in toxic reactions and allergic responses in previously sensitized individuals, especially in under cured appliances [39]. It is often difficult to differentiate between these two fundamentally different types of reactions because the clinical manifestations are similar i.e. redness and swelling of the affected mucosa. A differential diagnosis of fungal infections must also be made. Physical trauma caused by overextended or poorly fitting dentures may also present as local reactions. These are difficult to differentiate from other types of local lesions. It is important in this context to keep in mind that formaldehyde is a degradation product of several monomers used in dentistry, including denture-base polymers and restorative resin based composites. In fact, about half of all reported side effects to prosthodontic materials have been associated with polymeric materials [40]. Heat-cured acrylics are well tolerated by the gingival tissues in comparison with cold-cure acrylic resins which may result in gingival reactions [41].

The consequent diffused or localized burning sensation in the mouth because of direct mucosal irritation may be erroneously taken for the entity of "Burning Mouth Syndrome (BMS)". In fact the burning sensation may result from the intra-oral manipulation of resin or because of the presence of residual monomer. Consequently, this may elicit either an allergic response or cause direct irritation of the mucosa by the monomer or by the heat generated during its curing in the mouth [42]. In this case the obvious signs of inflammation and irritation for the burning sensation may be sufficient not to consider this as the entity of BMS. 
Other Materials: The most frequent allergy complained in dental practices is probably sensitivity to latex There are three basic categories of adverse latex gloves associated conditions: irritant, allergic and immediate, or type I hypersensitivity allergy. The first two types are painful and temporarily debilitating, but without potential for serious reactions. The third type the least common but the worst type of reaction, sometimes leading to anaphylaxis .Use of vinyl or nitril gloves is recommended, while it is advisable for severe sufferers to work in latex-free environment. [38]

Post endodontic restorations can be done by several dental restorations such as amalgam and composite fillings. Amalgam causes nearly 50\% death to the buccal epithelial cells after 15 min of insertion and this can be explained as, dental silver amalgam releases up to $70 \% \mathrm{Hg}$ vapors in the first day of filling insertion. Hg vapor more readily penetrates cellular membranes than inorganic mercuric salts because of its smaller size and high affinity for lipid membranes, so inhalation of $\mathrm{Hg}$ vapors results in greater $\mathrm{Hg}$ accumulation in all tissues [43].

Cytotoxicity of dimethacrylates such as TEGDMA and HEMA increases after a long exposure period. It has also been recognized that, composite resins are prone to enzymatic hydrolysis leading to the generation of toxic products such as methacrylic acid, which can under certain conditions be oxidized to produce formaldehyde as a by-product. Thus, resin biodegradation may play a significant role in producing changes in the oral environment [43].

CONCLUSION: Materials such as acrylics, ceramics, resin cements and implants represent a major advance in prosthodontics. Although these products may act as allergens in part of the population, one should keep in mind that every technology, no matter how beneficial, can exert a negative impact on some members of the population. The reality of public health will always involve balancing maximum benefit and minimum harm to the public health and well-being. Because allergy is a reality dentists have to deal with.

The following guidelines are proposed:

- Every prosthodontist should be familiar with the major signs and symptoms of allergic reactions, including anaphylaxis in the case that an allergic emergency should arise during a consultation. Previous allergic status of patients and personnel should be noted.

- Dental personnel should always keep records of dental materials used. If allergic reaction occurs, backtracking is necessary in ord er to identify the specific allergen.

- Do not mistake contact allergy for chronic trauma.

- Local exhaust ventilation systems can significantly reduce the peak concentration of acrylate vapor in the breathing zone of dental technicians.

- If sensitivity is suspected inform the patient about possible clinical tests to determine origin of allergy, e.g. acrylate patch testing. Delayed sensitivity may be prevalent in certain cases.

It is important to maintain, by keeping a national register, a record of all adverse reactions and side effects noted in institutions and practices. Similarly, for monitoring and evaluation of hazardous effects in dental personnel, their regular screening strategies need to be incorporated. There is a need for standardized criteria to assess hypersensitivity reactions in clinical dentistry. 


\section{REFERENCES:}

1. Larsson KS (1991) Potential teratogenic and carcinogenic effects of dental materials. Int Dent J 41:206-11.

2. Tai Y, De Long R, Goodkind RJ, Douglas WH (1992) Leaching of nickel, chromium, and berrylium ions from base metal alloy in an artificial oral environment. J Prosthet Dent 68:6927.

3. Wataha JC, Hanks CT (1996) Biological effects of palladium and risk of using palladium in dental casting alloys. J Oral Rehabil 23:309-20.

4. Rossow B, Koppang R (1973) Elution of cadmium from dentures.Scand J Dent Res 81:292-3.

5. Smith DC, Bains ED (1956) The detection and estimation of residual monomer in polymethyl methacrylate. J Dent Res 35:16 -25.

6. Axelsson B, Nyquist G (1962) The leaching and biological effect of residual monomer of methyl methacrylate. Odontol Revy 13:370-9.

7. Douglas WH, Bates JF (1978) The determination of residual monomer in polymethylmethacrylate denture base resins. J Mater Sci 13:2600-4.

8. Austin AT, Basker RM (1980) The level of residual monomer in acrylic denture base materials. Br Dent J 149:281 -6.

9. Fletcher AM, Purnaveja S, Amin WM, Ritchie GM, Moradians S, Dodd AW (1983) The level of residual monomer in self-curing denture base materials. J Dent Res 62:118 -20.

10. Koda T, Tsuchiya H, Yamauchi M, Hoshino Y, Takagi N,Kawano J (1989) High-performance liquid chromatographic estimation of elutes from denture base polymers. J Dent 17:84 -9.

11. Ruyter IE (1980) Release of formaldehyde from denture base polymers. Acta Odontol Scand $38: 17-27$.

12. Lygre H, Solheim E, Gjerdet NR (1993) Leaching of organic additives from dentures in vivo. Acta Odontol Scand 51:45 -51.

13. Parke DV (1968) The biochemistry of foreign compounds. New York: Pergamon Press Ltd; $p$. 11.

14. Gell PGH, Coombs RRA, Lachman LB (1975) Clinical aspects of immunology. Blackwell, Oxford.

15. Janeway CA Jr, Travers $P$ (1997) Immunobiology In: The immune systems in health and disease. Edinburgh, Churchill-Livingstone.

16. Tony Axell, Bert B., Sigfrid F., Bo Niklasson (1983) Standard patch test series for screening of contact allergy to dental materials. Contact Dermatitis 9(1): 82-84.

17. Sebastiano Gangemi, ElviraSpagnolo, Giulio Cardia (2009) Fatal Anaphylactic Shock Due to a Dental Impression Material. The International Journal of Prosthodontics 22(1): 33-34.

18. Aziza Al Mobeeriek,Hana Al-Elshiekh (1998) Adverse Effects Of Polysulfide Impression Materials:Case Report, 10(2),86-88

19. Hensten-Pettersen, A. Nilner, K. Moller, B (1990) Guinea pig maximization test with a polyether impression material. Scand Res 98(4): 356-62.

20. Phillips WR (1991) Skinner's science of dental materials. Philadelphia, W.B.Saunders Company.

21. Craig R, O'Brien W, Power (1992) J. Dental materials properties and manipulation. Mo sby.

22. N. Sarrami M. N. Pemberton M. H. Thornhill (2002) British Dental Journal 193(5): 257-259. 
23. Bergenholtz G (1989) Bacterial leakage around dental restorations- impact on the pulp. In: Anusavice KJ (ed). Quality evaluation of dental restorations. Chicago; Quintessence 243 - 52.

24. Johnson GH, Powell LV, DeRouen TA. (1993) Evaluation and control of post-cementation pulpal sensitivity: zinc phosphate and glass ionomer luting cements. J Am Dent Assoc 124:38 - 46.

25. Cornelis H. Pameijer (2012) A Review of Luting Agents. International Journal of Dentistry 752861.

26. Hensten-Pettersen A. (1992) Casting alloys: side effects. Adv Dent Res. 6: 38 - 43.

27. Werner Geurtsen (2002) Biocompatibility Of Dental Casting Alloys. Crit Rev Oral Biol Med 13(1):71-84

28. Kinnebrew M, Gettleman L, Carr RF,Beazley R (1984) Squamous cell carcinoma of the tongue in a young woman: Report of a case with etiologic considerations. Oral Surg Oral Med Oral Pathol. 58: 696 - 8.

29. Vasantha Vijayaraghavan, Ajay V. Sabane (2012) Hypersensitivity to Titanium: A Less Explored Area of Research. J Indian Prosthodont Soc. 12(4):201-207

30. Terry D. Rees (2011) Hypersensitivity to Dental Cast Metals: A Clinical Study. The Open Pathology Journal. 5:13-22

31. Prowse K, Allen MB, Bradbury SP. (1989) Respiratory symptoms and pulmonary impairment in male and female subjects with pottery workers' silicosis. Ann Occup Hyg 33:375-385.

32. Wagner MMF, Wagner JC, Davies R, Griffiths DM (1980) Silica-induced malignant histiocytic lymphoma: incidence linked with strain of rat and type of silica. Br J Cancer 41:908-917.

33. Tornling G, Hogstedt C, Westerholm P. (1990) Lung cancer incidence among Swedish ceramic workers with silicosis. International Agency for Research on Cancer 113-119.

34. Lever WF, Schaumber-Lever G. (1984) Histopathology of the skin. Philadelphia (PA): J.P. Lippincott Co. 221-224.

35. Shelley WB, Hurley HJ. (1996) The pathogenesis of silica granulomas in man: a non-allergic colloidal phenomenon. J Invest Dermatol 34:107-123.

36. Harmon SM, Pickett AB, Frost JM. (1983) Foreign-body (silica) granuloma of the lip. Oral Maxillofac Surg, 41:470-472.

37. Lonnroth, E.C., Shahnavaz, H(1997) Use of polymer materials in dental clinics. Swed. Dent. J. 21:149-150.

38. Goran Tosic. (2004) Occupational Hazards In Dentistry-Part One: Allergic Reactions To Dental Restorative Materials And Latex Sensitivity. Facta Universatatis 2(4):317-324.

39. Kaaber S, Thulin H, Nielsen E. (1979) Skin sensitivity to denture base materials in the burning mouth syndrome. Contact Dermatitis 5:90 - 6.

40. Hensten-Pettersen A, Jacobsen N. (1991) Perceived side effects of biomaterials in prosthetic dentistry. J Prosthet Dent. 65:138 - 44.

41. Zander HA. (1957) Effect of silicate cement and amalgam on the gingiva. J Am Dent Assoc. $55: 11$ - 5 .

42. Kotilainen R. (1972) Stomatitis prothetica and allergy. Proc Finn Dent Soc. 8:16.

43. Rokaya H. Ahmed, Mohammed I. Aref, Rania M. Hassan. (2010) Cytotoxic Effect of Composite Resin and Amalgam Filling Materials on Human Labial and Buccal Epithelium. Nature and Science 8(10):48-53. 


\begin{tabular}{|c|c|}
\hline Intra-oral reactions & $\begin{array}{l}\text { Lichen planus type reaction } \\
\text { Swelling, tenderness and/or reddening } \\
\text { Burning sensation and/or taste changes } \\
\text { Ulceration or blisters } \\
\text { other }\end{array}$ \\
\hline Face and/or Lip reactions & $\begin{array}{l}\text { Swelling, tenderness and/or reddening } \\
\text { Dermatitis, eczema or urticaria } \\
\text { Burning sensation and/or tingling } \\
\text { Ulceration or blisters } 6 \text { Headache, nausea and/or dizziness } \\
\text { Other }\end{array}$ \\
\hline Hands, wrists and/or finger reactions & $\begin{array}{l}\text { Dermatitis, eczema or urticaria } \\
\text { Itching, dry, cracked and/or burning skin } \\
\text { Swelling, tendern ess and/or reddening } \\
\text { Ulcers, blisters or vesicles } \\
\text { Other }\end{array}$ \\
\hline General reactions & $\begin{array}{l}\text { Breathing problems, wheezing and/or asthma } \\
\text { Runny, irritated eyes and/or nose } \\
\text { Coughing, sneezing and/or sore throat } \\
\text { Headache, nausea and/or dizziness } \\
\text { Other }\end{array}$ \\
\hline
\end{tabular}

Table 1 - Table of the signs and symptoms of adverse reactions to dental materials by location

\begin{tabular}{|l|l|l|l|}
\hline \multicolumn{1}{|c|}{ Element } & Systemic Toxicity & \multicolumn{1}{c|}{ Cytotoxicity } & \multicolumn{1}{c|}{ Allergies } \\
\hline Chromium & $\begin{array}{l}\text { Cr(III) Salts: Low } \\
\text { Cr(VI) Salts: High }\end{array}$ & $\begin{array}{l}\text { Cr(III) Salts: Low } \\
\text { Cr(VI) Salts: High }\end{array}$ & Cr(VI): Common \\
\hline Gold & Very low & Low & Rare \\
\hline Cobalt & Low & High & $3 \%$ of population \\
\hline Molybdenum & Low & Low & None Reported \\
\hline Nickel & $\begin{array}{l}\text { Dust Carcinogenic } \\
\text { Otherwise low }\end{array}$ & Low & Very Common \\
\hline Palladium & Very Low & Very Low & $\begin{array}{l}\text { Prevalence unknown, } \\
\text { Those allergic to nickel are } \\
\text { more commonly affected }\end{array}$ \\
\hline Platinum & Very Low & Low & $\begin{array}{l}\text { Metal: Very rare } \\
\text { Compounds: Common }\end{array}$ \\
\hline Ruthenium & Very low & low & None reported \\
\hline Silver & Low & Very high & Rare \\
\hline Titanium & Very Low & Very Low & Very rare \\
\hline Zinc & Very Low & High & Very rare \\
\hline Table $2:$ An & & &
\end{tabular}

Table 2: An overview of the biological effects of alloy components used in prosthodontics 


\section{REVIEW ARTICLE}

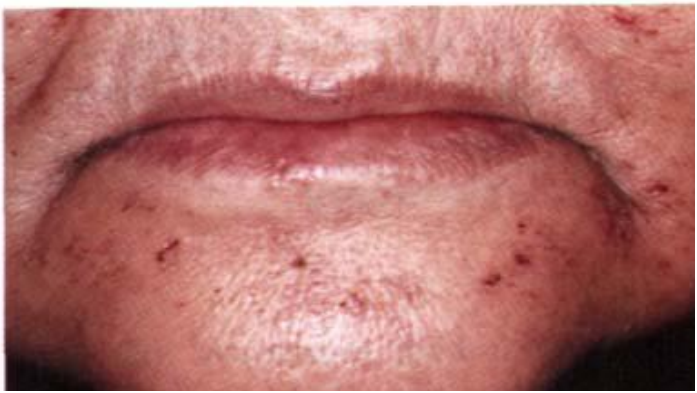

Fig. 1 Peri-oral erythema and ulcerations.

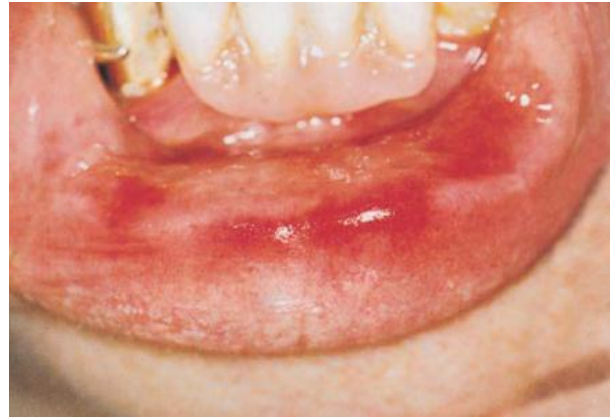

Fig.3. Burn ing Mouth Syndrome

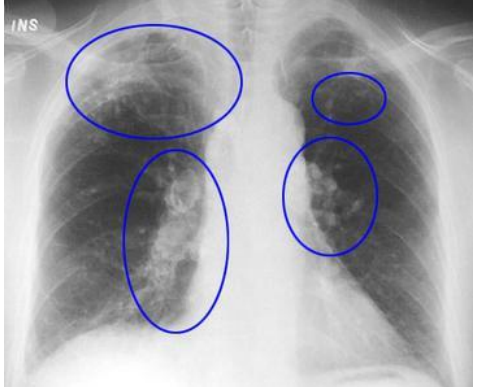

Fig.2. Pulmonary Silicosis

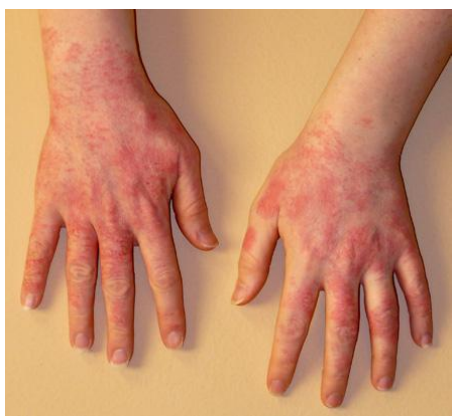

Fig.4 Allergy to late $\mathrm{x}$ loves

\section{AUTHORS: \\ 1. Soniya R. Niraspatil \\ 2. Pravin S. Purnale \\ 3. Aruna J. Bhandari \\ 4. Gangadhar S.A. \\ 5. Bharat A Deosarkar}

\section{PARTICULARS OF CONTRIBUTORS:}

1. Post Graduate Student, Department of Prosthodontics, Rural Dental College, PIMS, Loni.

2. Post Graduate Student, Department of Prosthodontics, Rural Dental College, PIMS, Loni.

3. Professor and Guide, Department of Prosthodontics, Rural Dental College, PIMS, Loni.

4. Professor, HOD and Principal, Department of Prosthodontics, Rural Dental College, PIMS, Loni.
5. Post Graduate Student, Department of Endoodontics, Sawangi.

\section{NAME ADDRESS EMAIL ID OF THE CORRESPONDING AUTHOR:}

Dr. Soniya R. Niraspatil, Post Graduate Student,

Departm ent of Prosthodontics,

Rural Dental College,

Pravara Institute of M edical Sci ences,

Loni - 413736, Tal - Rahata,

Dist - Ahmednagar.

Email-dr.soniya87@gmail.com

Date of Submission: 17/09/2013.

Date of Peer Review: 19/09/2013.

Date of Acceptance: 22/10/2013.

Date of Publishing: 29/10/2013 